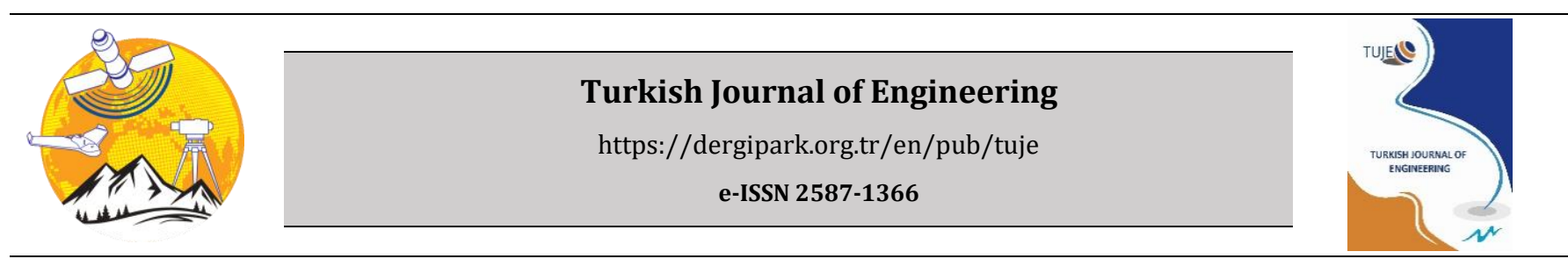

\title{
Risk assessment with the fuzzy logic method for Ankara OIZ environmental waste water treatment plant
}

\author{
Fatma Erdem \\ Turkish Medicines and Medical Devices Agency, 06520, Sihhlye, Ankara, Turkey
}

\section{Keywords}

Risk management

Modelling

Fuzzy logic

Waste water treatment plant

\begin{abstract}
In this study, occupational safety risk assessment has been performed for Ankara Chamber of Industry 2nd and 3rd Organized Industrial Zone (OIZ) Regional Directorate - Environmental Waste Water Treatment Plant (WWTP) by fuzzy logic method. In the literature, there are lots of risk assessment methodologies. These methods for the risk level do not give accurate results in systems such as WWTPs with a lot of complexity and variability. Also, these methods include strict lines and are not reflecting the practical issues of the real-world applications. For this reason, these methods are to be adopted by the use of fuzzy logic. Fuzzy Logic Risk Analysis Model which gives more realistic results compared to traditional methods based on probability. For fuzzy safety risk assessment firstly membership functions for input and output are created and values risk assessment input data is blurred then Fuzzy Risk Priority Number (FRPN) is determined in the Matlab 2013a software program. In this study a risk matrix merged with Fuzzy Logic model is developed to enhance the risk assessment process which is dealing with uncertainties that arise in each phase of the risk assessment process. RPN values were investigated and compared by $5 \times 5$ matrix and fuzzy logic method.
\end{abstract}

\section{INTRODUCTION}

As a general definition, risk is a negative possibility that is not desired to be encountered (Łój-Pilch at al. 2018). As in every field, it becomes very important in the disruption of urban services that are carried out without risk and in situations that directly concern public health (Łój-Pilch and Zakrzewska 2020). Water and wastewater management is at the top of the list of urban services involving high risks. Disruption of the sustainability of these services, which are closely related to the environment and human health or any decrease in service quality, may have negative consequences. Environmental damage or health loss that may occur in case of risk is much more important than financial losses (Kudłak et al. 2016, Cossio et al. 2019).

The term "Risk Management" was first used in the United States of America in the late 1950s (Nicoleta et al. 2020). In the early days, it was dealt with insurance and took part in insurance. Thus, risk management can be defined as planning, organizing, managing and controlling the resources and activities required to control the unexpected losses that may occur in the organization at the lowest cost. Risk management includes the stages of identifying and evaluating risks, responding to risks, regularly reviewing and reporting risks (Emhan 2009).

Water resources in the world are decreasing rapidly. Among these resources, water resources of potable quality decreased and reached the point of depletion (Yllmaz 2015). On the other hand, waste water released to receiving environments without being treated in a way causes pollution of water resources whose amount is decreasing day by day and deserve more interest recently (Ozkan et al. 2013). For this reason, waste water should be treated in order not to contaminate existing water resources and to use water resources more efficiently (Edokpayi et al. 2017).

Necessary precautions should be taken in order to create a healthy and safe work environment in WWTPs 
and to prevent possible work accidents (Malakahmad et al. 2012).

In this context, safety measures to prevent accidents and dangers that may occur during the maintenance, repair and operation processes of WWTPs should be acted within the scope of occupational health and safety (OHS) (Güner 2018). WWTPs, which are classified as "very dangerous", contain many risks regarding occupational health and safety in terms of processes and working conditions. In determining the risks that may occur in WWTPs, in addition to the effects on occupational and worker health, it is necessary to determine the scope and size of their effects on the environment. Considering the negative environmental effects of the dangers in these facilities, it is important to re-evaluate and prioritize the risks. In occupational and worker safety, including environmental impacts as well as the activity and employee safety in the risk analysis will benefit both decision-makers and managers (ElQuliti et al. 2016).

Many neural network applications can used for, bioprocesses control and risk management systems (Özkan et al. 2010, Mete et al. 2012). Fuzzy logic is one of them and has proven to be very successful in a wide range of applications, with much commercial success. Risk analysis is a complex task that entails the consideration of many parameters which are, more often than not, very difficult to quantify. Fuzzy logic presents a natural way of modelling these vaguenesses, while also ensuring that human creativity and intuitivity, which is an essential ingredient for successful risk analysis. In literature, Bavani and Tabesh 2012, produced an algorithm by fuzzy for the risk management of the WWTP. Comprising probability of failure, intensity of probable damages and vulnerability of element were used for the calculation of operational risk and results showed that proposed algorithm is successful for risk management. Cabanillas et al. 2012, used fuzzy logic with a new methodology. Algorithm was based on 22 WWTP datas. Results showed that new method with fuzzy logic showed better and practical results than solid method. Alavipoor et al. 2016, used Fuzzy-WRASTIC new model for the risk management of Geographic Information System) environment. Surface water contamination risk in this area was divided into four ranges: low, medium, high and very high. High risk zones are much more than the others and the reasons discussed. Yel and Yalpir 2011, used fuzzy logic for municipal wastewater treatment plant (MWTP). A fuzzy-logic-based diagnosis system was developed to determine the primary treatment effluent quality in a MWTP. The measured data of variables were implemented into the Fuzzy Inference System (FIS) with Mamdani's method. The output approximations to real data remained in an acceptable range for a MWTP performance (89-96\%). The averages and standard deviations of the model were also approximated closely as 93-98\% and 89-97\%, respectively. The resulting configuration proved a good modeling approach for MWTP effluent quality prediction15. Ghandi and Roozbahani 2020, used fuzzy Promthee V (Preference Ranking Organization Method for Enrichment Evaluation) technic for the selection of the most appropriate drinking water supply strategies in crisis conditions and applied for Tehran city. Model was solved through fuzzy and non-fuzzy method. Mirghafouri and Kousha 2015, used Fuzzy FMEA-AHP algorithm the risk of water transmission pipeline to Yazd. Results showed that failure of electromotor and electricity panels in pumping stations, reduction of height of river water level in water harvesting site and breakdown of main faucets in pipeline path are on high priority.

In this study risk management was investigated for Ankara Chamber of Industry 2nd and 3rd Organized Industrial Zone (OIZ) Regional Directorate WWTP by fuzzy logic method. The contribution of this paper to the literature is important due to the number of WWTPs operated in Turkey is increasing day by day. Each of the treatment plants are potential risk to safety. WWTPs contain many hazards from the operation, maintenance and repair in terms of both occupational health, safety and environment. Ankara OIZ Environmental WWTP is a new and big WWTP in Ankara and outlet stream is connected to Ankara Stream which joins with Sakarya river and pours into Sarıyer dam. With such risk analyzes carried out in this plant, it is aimed to reduce accidents and increase the working efficiency. Also, fuzzy $5 \times 5$ matrix type risk assessment method is never used for WWTP risk management studies before. For this first of all, the hazards were determined and then the risk value was calculated considering the probability of accidents and the effects of severity after they occur. The probability and severity values, which were the input data, were blurred and membership functions were created for the probability, severity and FRPN. Triangular membership functions were defined one by one for grading levels that are very low, low, medium, high and very high. A possible solution is proposed by modifying the risk matrix using a fuzzy logic model to deal with the uncertainties.

\section{METHOD}

\subsection{Study Area: Waste Water Treatment Plant}

The analyzed WWTP is located in Sincan. Domestic and industrial wastewater originating from factories and facilities in Ankara Chamber of Industry 2nd and 3rd Organized Industrial Zone is treated in a WWTP with a capacity of $2500 \mathrm{~m}^{3} /$ day by Advanced Biological Treatment process. The total industrial area in ASO (Ankara Chamber of Industry) 2nd and 3rd OIZ is approximately $400 \mathrm{ha}$, and there are 321 industrial parcels varying between $10000 \mathrm{~m}^{2}$ and $200000 \mathrm{~m}^{2}$ can be seen in Fig. 1. Currently, the number of active facilities is 90. The current amount of treated water is 1900 $\mathrm{m}^{3}$ /day. If the pollutant concentrations of the participant activities meet the discharge standards defined in the wastewater management system, they are connected to the sewerage system without any pre-treatment. The pollution values of the wastewater originating from the facilities that cannot meet this requirement are reduced to the discharge standard limits and released to the environment. Risk datas were defined with the expert about compressor, pump, electricity, lighting, wet floor etc. such as general risks for treatment plants. 


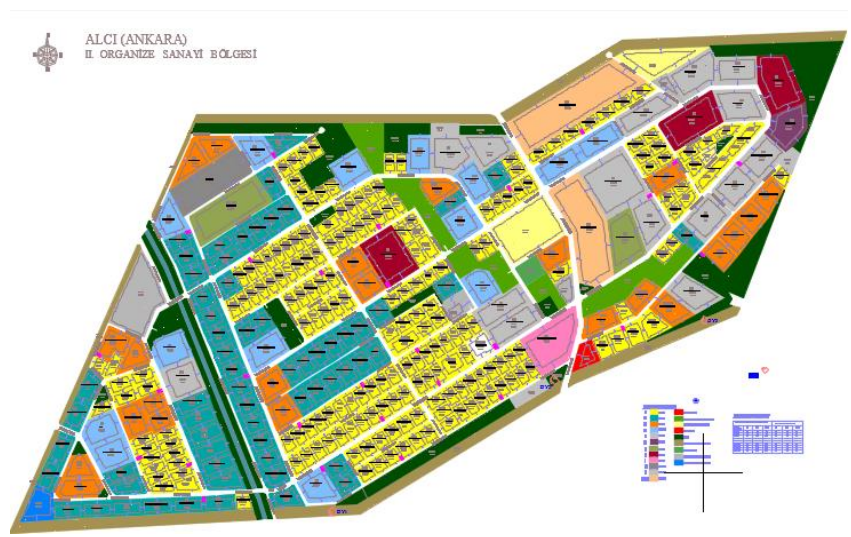

Figure 1. WWTP plan

\subsection{Hazard identification for WWTP}

Hazards were grouped under 10 headings as electricity, chemical substances, compressor, pump, forklift, crane, stairs, natural gas, manual handling and general security as percentage distribution was shown in the Fig. 2. These categories were detailed and then the distribution of risk levels were analyzed. For ex: for electricity 14 hazards identified such as conducting electrical work by incompetent persons, not conducting electrical wiring and grounding control, not providing employees with training to work safely with electricity. For natural gas 2 hazard were identified such as, lack of emergency exit signs and directions and unsuitable emergency exits and doors. For manual handling the working area was not suitable for safe load transportation, the material being transported was not suitable for manual transportation, the maximum load limit per worker was exceeded, the employees did not have enough training, the articulation to take/drop the load, etc. 12 hazards were identified. For stairs, 11 hazards were identified such as not using ladders in accordance with the standards, not being able to reach the work area while on the ladder, using ladders in unsuitable weather conditions, not choosing ladders suitable for the electrical environment. General security was included some points about office, building and personnel.

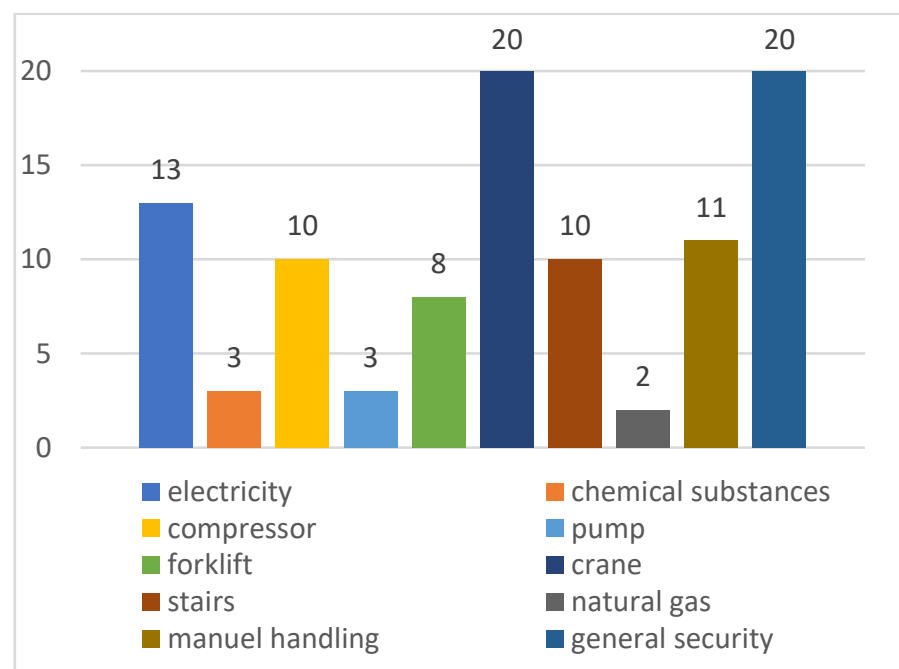

Figure 2. Distribution of hazards according to categories for WWTP

\subsection{Analysis of Risks}

Risk assessment is a process that includes the necessary studies to determine the dangers that exist in the workplace or that may come from outside, the factors that cause these hazards to turn into risks and the risks arising from the hazards by analyzing and rating them and determining the control measures (Falakh and Setiani 2018).

\subsubsection{Type(5x5 Matrix)}

Risk matrices are a method of combining qualitative or semi-quantitative outcome/probability ratings for determining risk level or risk rating. $5 \times 5$ matrix is especially used to evaluate cause and effect relationships. The risk score is calculated on the basis of probability and severity parameters. The work should not be started until the identified risk is reduced to an acceptable level and should be stopped immediately if there is an ongoing activity. In the L matrix method, the probability and severity parameters are evaluated on a scale of 1 to 5 and the risk score is calculated by multiplying them by Eq.1 $(\mathrm{Ak}, 2020)$.

RPN = Severity $x$ Probability

RPN is a number indicating the level of criticality. RPN in the calculation of the value, verbal or defined as probability a certain number of risks factors. The values assigned in the range are retrieved. For each type of error with RPN risks are identified starting from the owner of RPN minimizing in the short term, in the long run removal, corrective to be taken for measures are determined (Kursun et al. 2016). Probability verses severity $5 \times 5$ matrix was given at Fig. 3 .

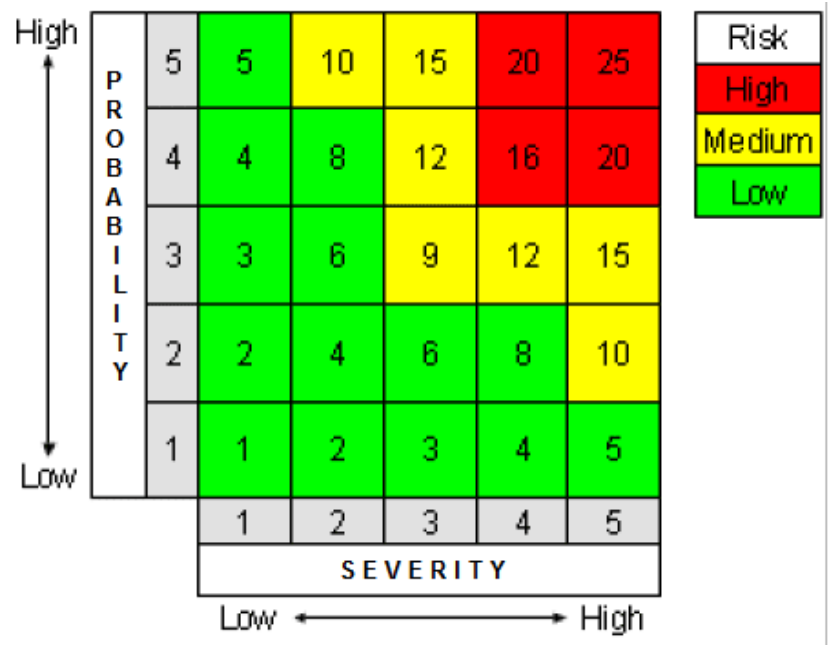

Figure 3. Probability verses severity $5 \times 5$ risk matrix

Limitations of risk matrix is that the data used in the risk matrix have different degrees of uncertainty. Some of the values are known with precision, others are wild guess. Generally, matrix use three colours (e.g., red, yellow and green) for representing the level of risk. Also, individual people have different risk tolerances. This can further distort how matrix can be used. People with low risk tolerance will over rate risks, while the people with 
high risk tolerance will under rate risks. Fuzzy logic is a set of mathematical principles for knowledge representation based on degrees of membership. It deals with degrees of membership and degrees of truth. It reflects how people think and attempts to model our sense of words, our decision making and our common sense (Kumar and Shrihari, 2016).

\subsubsection{Fuzzy Risk Analysis Methodology}

The first step in preventing accidents is to make a suitable and adequate risk assessment. Risk assessment should be made taking into account all the dangers and risks of the employees, other people (visitors, anyone in the environment) (Abuzerr et al. 2020). In the analysis of risks; after the hazards are identified, the risk value is calculated by taking into account the probability value of the accidents and the effects of severity after they occur (Stamatis, 1995).

Probability: The occurrence of a hazard is based on likelihood. This possibility should be evaluated together with the conditions and factors that constitute this hazard. Rating steps for probability can be seen from Table 1.

Table 1. Rating steps for probability

\begin{tabular}{llc}
\hline & \multicolumn{1}{c}{ Meaning } & Value \\
\hline Expected & Will occur & 5 \\
Likely & Most likely & 4 \\
Often & Possibilities are happening or can & 3 \\
Unlikely & occur & \\
It is less likely to occur & 2 \\
\hline
\end{tabular}

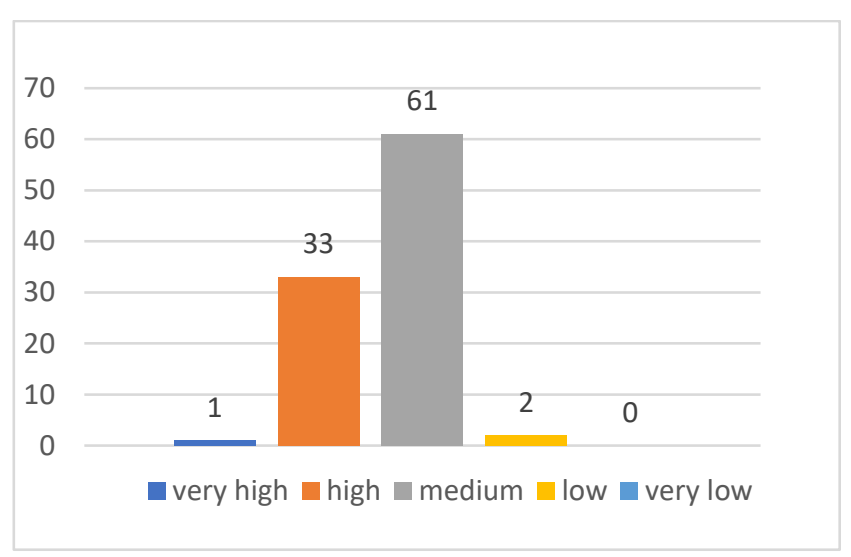

Figure 4. Distribution of accident probability values

Distribution of accident probability values was given at Fig. 4 for WWTP. From a total of 97 risks; one of them is shown as "Very High" with 5 likelihood values, 33 as "High" with 4 probability values, 61 as "Medium" with 3 li probability values, and 2 as "Low" with 2 probability values.

Severity: In case of occurrence of danger, it indicates the degree of damage to people exposed to danger and the environment. This weight is determined on the basis of experts' opinions, relevant scientific data, and published experiences. Rating Steps for severity is given Table 2.

Table 2. Rating steps for severity (Subriadi and Najwa 2020)

\begin{tabular}{llc}
\hline & \multicolumn{1}{c}{ Meaning } & Value \\
\hline Fatal & $\begin{array}{l}\text { Meaningful inconvenience } \\
\text { anxiety }\end{array}$ & 5 \\
Major & $\begin{array}{l}\text { Major injury } \\
\text { Requiring inpatient treatment, but } \\
\text { Moderate }\end{array}$ & 4 \\
requiring clinical treatment \\
Minor & Minor injury & \\
Insignificant & No impact & 3 \\
\hline
\end{tabular}

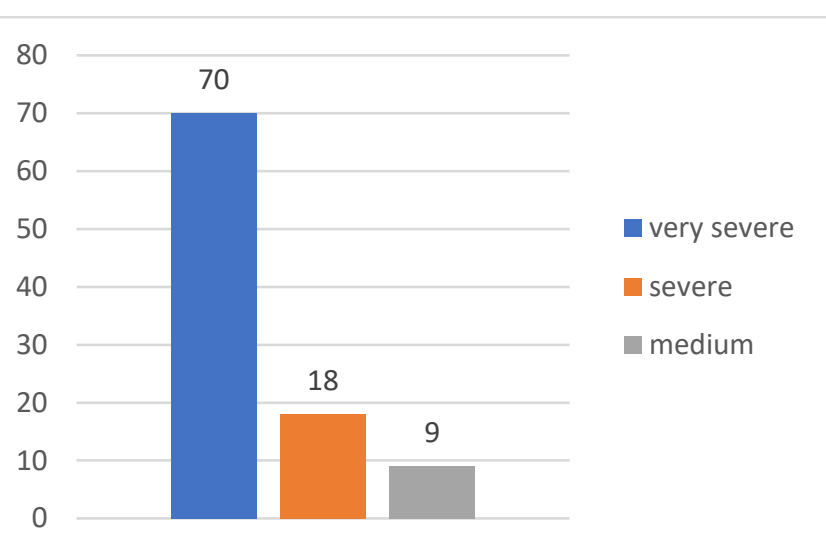

Figure 5. Distribution of severity values

Distribution of severity values was given at Fig. 5 for WWTP. From a total of 97 risks; 70 of them have a "very severe" level with 5 severity values, 18 of them have a "severe" level with 4 severity values, and 9 of them have a "medium" level with 3 severity values.

As it can be seen in Fig. 6, a suggested fuzzy model consists of different steps.

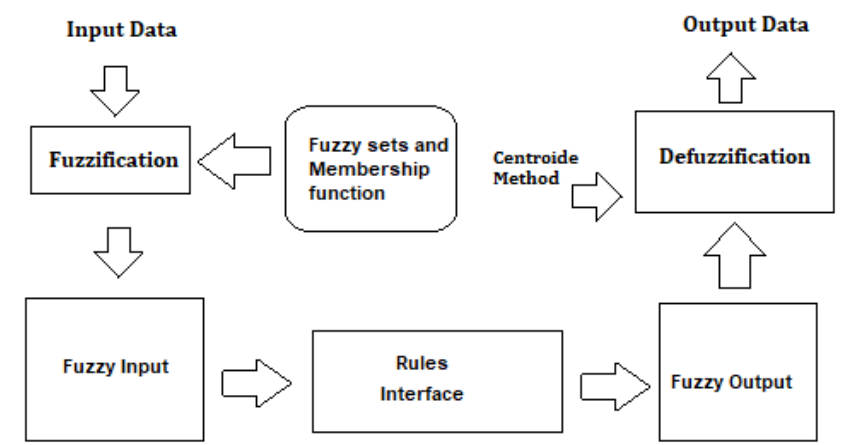

Figure 6. Representation of the fuzzy methodology (Radionovs and Rebrov, 2014).

1) Fuzzyfication, was a defining moment of membership functions and fuzzy sets of severity, probability and fuzzy RPN (FRPN).

2) Evaluation of fuzzy rule, using IF-THEN rule where IF was a variable of fuzzy input while THEN

was a variable of fuzzy output. All combinations must be grouped to produce fuzzy rules. 
3) Defuzzyfication, with input defuzzyfication that was the fuzzy set obtained from the composition of fuzzy rules, while the output was the number in the fuzzy set. The technique used in this study was the Centre of Gravity (Centroid) (Suryoputro et al. 2019).

All these steps are carried out using the fuzzy toolbox that is present in Matlab (Shang and Hossen, 2013).

\section{RESULTS and DISCUSSION}

\subsection{Analysis of Risk Assessment with Fuzzy Logic Method}

Fuzzy Inference is the process of getting the equivalent of the input data in the rule base. Fuzzy inference system window "FIS Editor" was used in MATLAB for this process in the study. Fuzzy is designed in order to acquire the highest FRPN value which will be used as the focus of enhancements to reduce the probability of occurrence of some kind of failure for a second time (Balaraju et al, 2020). A model that was built in the techniques of fuzzy has 2 inputs (severity and occurence) and 1 output FRPN.

In this analysis, rule bases were created from the input data with Mamdani and the values in the risk analysis were calculated one by one. In practice, the input data probability and severity values, were blurred and membership functions were created for the probability, severity and FRPN. Triangular membership functions are defined for grading levels of very low, low, medium, high and very high.

In the triangle membership function for probability

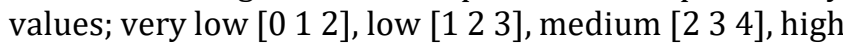
[3 4 3 5 ] and very high probability value parameters [4 5 5] were assigned. MATLAB software blurring operation window of the probability value input data was shown at Fig. 7.

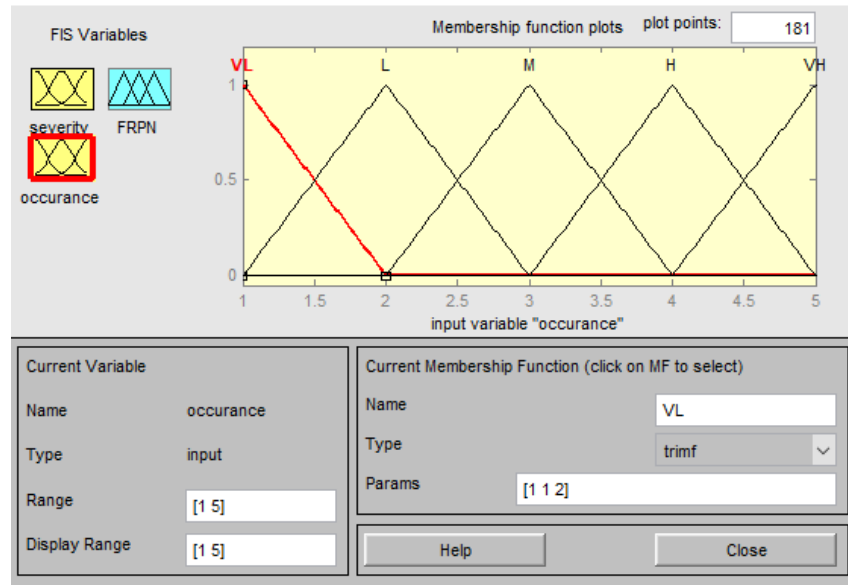

Figure 7. Program screen of probability input values

The severity values are in the triangle membership function; for negligible severity value [0 $\left.\begin{array}{lll}0 & 1 & 2\end{array}\right]$, for mild severity value [ $\left.\begin{array}{lll}1 & 2 & 3\end{array}\right]$, for medium severity value [2 34 ], for high severity value [3 4 5] and very high severity value parameters [ [ $\left.\begin{array}{ll}4 & 5\end{array}\right]$ ] are assigned for. In Fig. 8, the blurring operation writing window of the MATLAB software program severity value input data was shown.

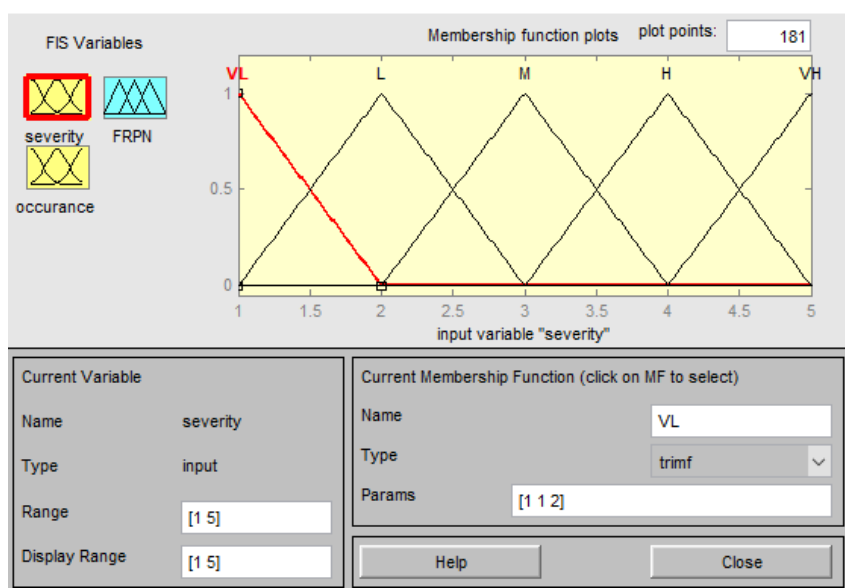

Figure 8. Program screen of severity input values

The assignment of FRPN is as follows: $[0,1,2]$ range is very low, $[1,2,3]$ range is low, $[2,3,4)$ is medium, $[3,4,5]$ is high, $[4,5]$ is very high on the basis of definitions. After defining the parameters of the input values of probability, severity and risk priority number, in the triangle membership function and the verbal variables corresponding to these parameters, the possible situations were evaluated and 125 rules have been defined, program output was given at Fig. 9.

Firstly, the input values, which are severity and probability, are blurred using fuzzy expressions, membership degrees in the range of $[0,1]$ are given to variables. Then, using operations, rule bases are determined. While creating rule bases and/or its connectors, the operator "and" is implemented (Fig.10).

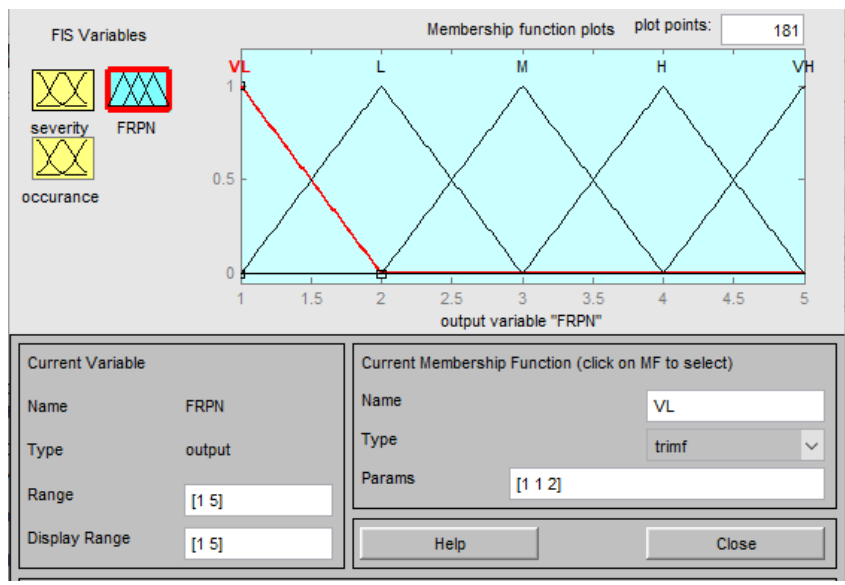

Figure 9. Program screen of FRPN Values

Estimated output with different input variables values can be observed from Fig. 12 for compressor. When maintenance and controls are disrupted and probability 4, severity 5; FRPN number was 4.68 .

The thee-dimensional risk matrix formed as a result of the obtained results was given in Fig. 13. When the Fig. 13 was examined if If $1<\mathrm{FRPN} \leq 2$, the risk is medium. If $2<$ FRPN $\leq 3$, the risk is moderately high and necessary measures should be taken immediately and the risk should be tried to be reduced. If $3<$ FRPN $\leq 4$, it is high. The risk in this area is unacceptable. Low, medium, medium high and high levels are expressed in dark blue, blue, green and yellow colors, respectively. However, in accordance with fuzzy logic theory, transitions to different levels of risk are not sudden and using exact 
color separations; It was made in a way to show the blur by opening the color tones.

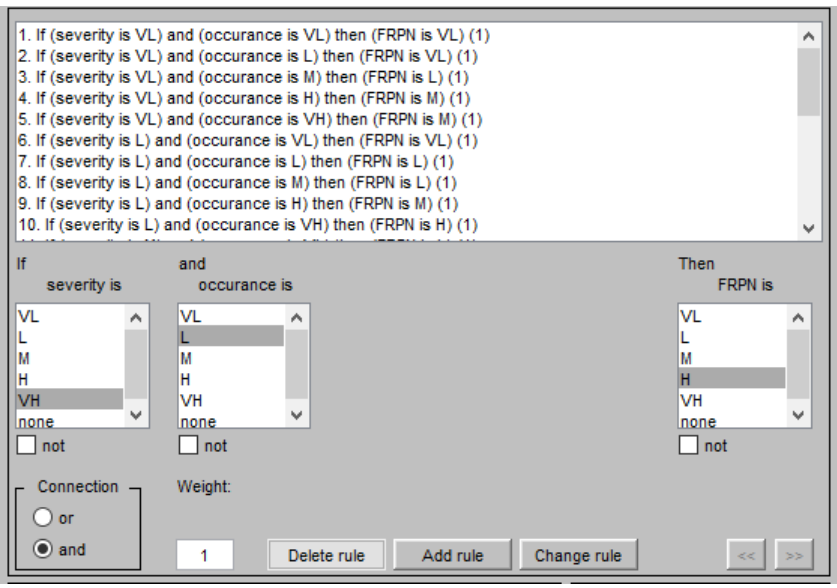

Figure 10. Fuzzy rule base window

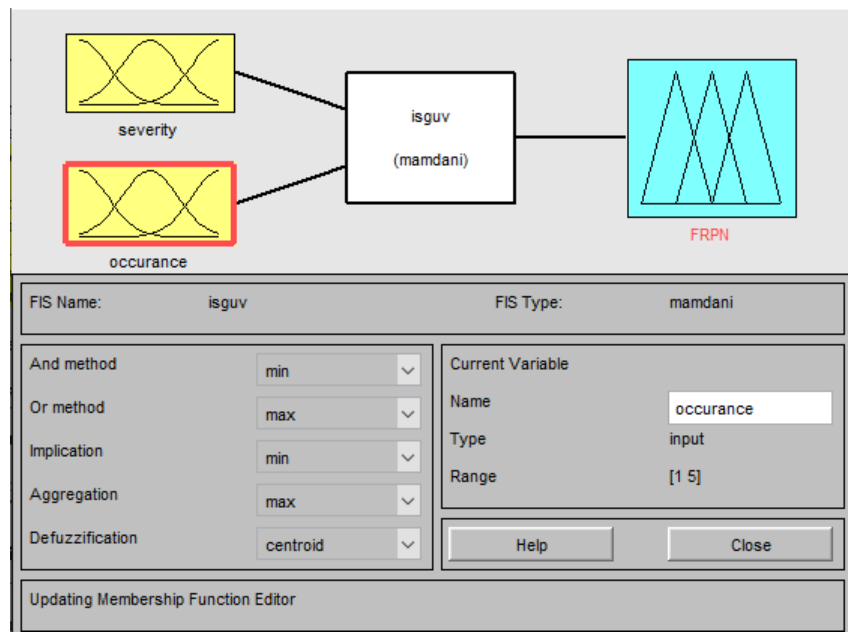

Figure 11. Program screen of FRPN Values by Mamdani fuzzy inference system

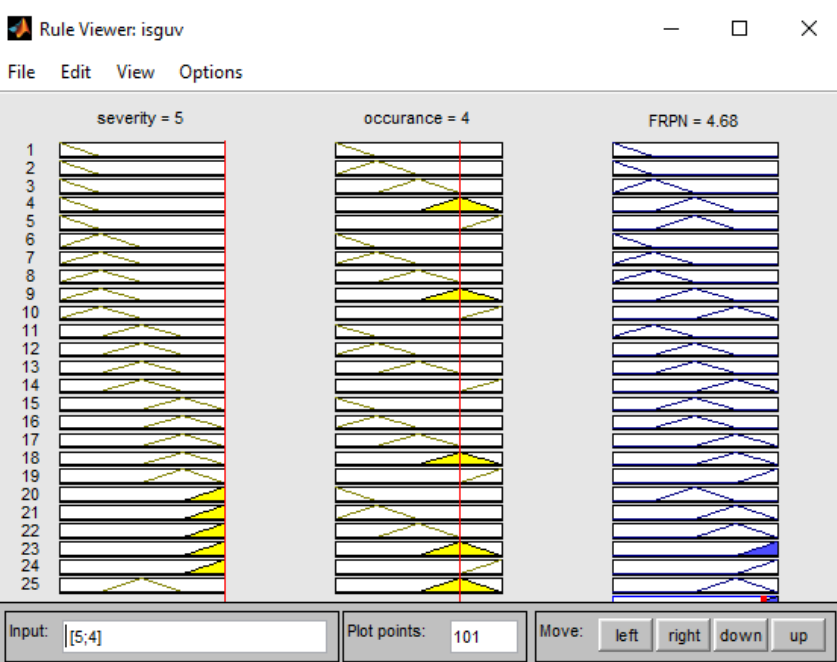

Figure 12. Inputs and output views of risk priority in matlab for compressor

The RPN values obtained is shown at Table 3 . Although the risks have the same probability and severity values, different results are obtained when $5 \times 5$ matrix and fuzzy calculations are carried out in the determination of the risk magnitudes. When $5 \times 5$ matrix RPN results are evaluated, it is observed that the RPN values vary between 9 and 20 and for electricity RPN is
20, according to Figure 3 it is in high-risk category. FRPN is 4.68 and it has high risk category too. For pump, forklift and crane according to $5 \times 5$ matrix method they are in medium risk category but according to FRPN they are in high-risk category. Construction machines such as pumps, forklifts, cranes have an important share in the scope of occupational safety due to the accidents they can cause, and regular maintenance is very important for them in terms of both working and preventing accidents.

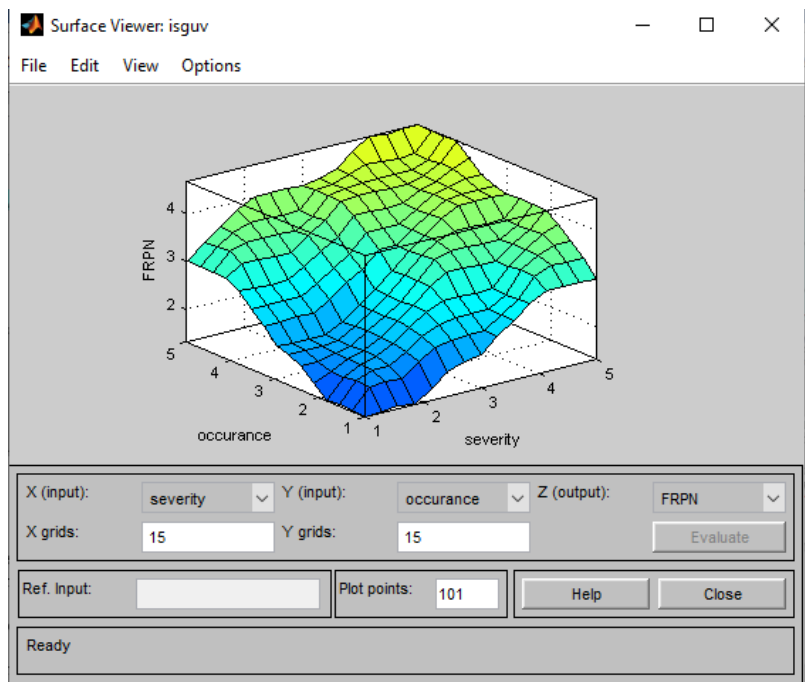

Figure 13. Result surface

Table 3. RPN values

\begin{tabular}{lcc}
\hline \multicolumn{1}{c}{ Risk } & FRPN & RPN \\
\hline Electricity & 4,68 & 20 \\
Chemical & & 15 \\
Substances & 4 & \\
Compressor & 4,68 & 20 \\
Pump & 4 & 15 \\
Forklift & 4 & 15 \\
Crane & 4 & 15 \\
Stairs & 4 & 15 \\
Natural Gas & 4 & 10 \\
Manuel Handling & 3 & 9 \\
General Security & 4 & 12 \\
\hline
\end{tabular}

When severity values are plotted against probability in risk structuring (Fig. 14), it is seen that most risks are at the boundary of categories. This creates lot of uncertainties in the overall risk assessment process. Risk matrix can be modified to avoid this problem. RPN calculation is only done by multiplying the severity and occurrence alone and irrespective of the degree of importance of each input. This method is based on human thinking and feeling, the project faces a vague imprecise concept and a quantitative value cannot be assigned to triple parameters; therefore, fuzzy theory is used as a valuable tool for calculations in uncertainty mode. Fuzzy logic was with the risks the measures needed to eliminate the risks are also blurred. Danger factor weights of the sources were taken into account.

In literature there is limited risk management study for WWTPs. Güner 2018, used 5x5 matrix method, Shinta et al. 2019, Asgarian et al. 2017, used traditional FMEA (Failure Mode and Effect Analiysis) method. In this study 
fuzzy $5 \times 5$ matrix type risk assessment method is used which is never used for wastewater treatment risk management studies before. Fuzzy provides more accurate and better results than traditional methods.

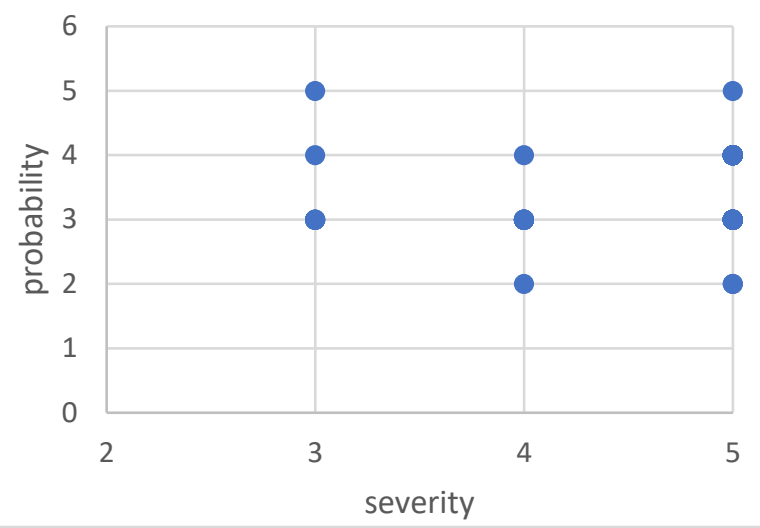

Figure 14. Risk matrix with different risks categories

\section{CONCLUSION}

The objective of this study is to develop a fuzzy logic system capable of analyzing and evaluating risks in WWTP. WWTPs are extremely important for general public health also necessary measures must be taken for safety and healty work conditions in WWTPs for employees and environment. This study is important because of the limited number of literature studies available. A fuzzy approach using linguistic variables has been proposed to eliminate the difficulties encountered in calculating a precise risk score and determining the measures to be taken, and to reduce the differences in expert opinion and combine them into a common denominator. RPN values investigated through Fuzzy logic and 5x5 matrix. RPN defines how the risk will affect the project objectives. The input data may also uncertainties and guesses. A false rating of a risk may have serious impact on the project. Hence the risk impact must be calculated by using mathematical models. The fuzzy logic is such a mathematical tool which can handle the uncertain data and provides solution reasonable manner which is similar to human thinking. Fuzzy logic brings a point of view where the boundaries are stretched by removing the exact boundaries. With this flexibility, the user can use the risk matrix more easily without any confusion.

An improved approach could be applied in future studies, such as artificial intelligence methods; fuzzy integrals, new fuzzy algorithms, genetic algorithm, artificial neural network. Especially, artificial neural network can help us in the field of risk management. When we have the correct data and we tuned the artificial neural network very well, the results of calculation can help us in the decision-making process.

\section{ACKNOWLEDGEMENT}

The author would like to thank Ankara Chamber of Industry 2nd and 3nd Organized Industrial Zone (OIZ) Regional Directorate WWTP, Environmental Management and Treatment Manager Enise Dilek ESEN and Occupational Health and Safety Specialist Meltem ATAGÜN for the provided data.

\section{Conflicts of interest}

The author declares no conflicts of interest.

\section{REFERENCES}

Abuzerr S, Hadi M, Zinszer K, Nasseri S, Yunesian M, Mahvi AH, Nabizadeh R, Hussien Mohammed S (2020). Comprehensive risk assessment of healthrelated hazardous events in the drinking water supply system from source to tap in Gaza Strip, Palestine. Journal of Environmental and Public Health, 1-10.

Ak M F (2020). Comparison of Risk Assessment Methods within the Scope of Occupational Safety in the Construction Sector. Avrupa Bilim ve Teknoloji Dergisi, (18), 272-282

Alavipoor F S, Ghorbaninia Z, Karimi S, Jafari H (2016). Surface water contamination risk assessment modeled by Fuzzy-WRASTIC. Water Environ. Res., 88, 589-601.

Asgarian M, Tabesh M, Roozbahani A, Bavani E B (2017) Risk Assessment and Management of Wastewater Collection and Treatment Systems Using FMADM Methods. Iran. J. Sci. Technol. Trans. Civ. Eng., 42, 5571.

Balaraju J, Govinda Raj, M \& Murthy C S N (2020). Prediction and Assessment of LHD Machine Breakdowns Using Failure Mode Effect Analysis (FMEA).

Bavani E B \& Tabesh M (2012). Risk Assessment and Management of Wastewater Treatment Plants (WTPs) Using a Fuzzy Multi-Attribute DecisionMaking (FMADM) Approach. 10th International Conference on Hydroinformatics.

Cabanillas J, Ginebreda A, Guillén D, Martínez E, Barceló D, Moragas L, Robusté J, Darbra R M (2012). Fuzzy logic based risk assessment of effluents from wastewater treatment plants. Science of the Total Environment, 439, 202-210.

Cossio C, Perez-Mercado L F, Norrman J, Dalahmeh S S Vinnerås B, Mercado A \& McConville J (2019). Impact of treatment plant management on human health and ecological risks from wastewater irrigation indeveloping countries-Case studies from Cochabamba, Bolivia. International Journal of Environmental Health Research, 29, 1-19.

Edokpayi J, Odiyo J, Durowoju O (2017). Impact of wastewater on surface water quality in develocountries: A case study of South Africa. Environmental Science, 1.

El-Quliti S A, Basarwan R, Alzahrani H, Alzahrani S, Badr F (2016). Procedure for Hazard Identification and Risk Assessment in Wastewater Treatment Planting Saudi Arabia, International Journal of Scientific And Technical Research In Engineering (IJSTRE), 1, 1-10.

Emhan A (2009). Risk yönetim süreci ve risk yönetmekte kullanilan teknikler. Atatürk Üniversitesi İktisadi ve İdari Bilimler Dergisi, 23, 209-219. 
Falakh F \& Setiani 0 (2018). Hazard identification and risk assessment in water treatment plant considering environmental health and safety practice. E3S Web of Conferences.

Ghandi M \& Roozbahani A (2020). Risk Management of Drinking Water Supply in Critical Conditions Using Fuzzy PROMETHEE V Technique. European Water Resources Association (EWRA), 34, 595-615.

Güner E D (2018). Environmental risk assessment for biological wastewater treatment plant. Pamukkale University Journal of Engineering Sciences, 24, 476480.

Kudłak B, Wieczerzak M, Yotova G, Tsakovski S, Simeonov V \& Namieśnik J (2016). Environmental risk assessment of Polish wastewater treatment plant activity. Chemosphere, 160, 181-188.

Kumar S S \& Shrihari S (2016). Standardisation of Risk Assessment Process by Modifying The Risk Matrix, International Journal of Advance Research in Science and Engineering, 5(1), 148-158.

Kursun B, Kurt U, Guvercin S, Okten K, Akgul S \& Yildiz A (2016). An application for the failure mode and effects analysis integrated with the grey relational analysis. Trakya University Journal of Engineering Sciences, 17, 35-44.

Łój-Pilch M \& Zakrzewska A (2020). Analysis of risk assessment in a municipal wastewater treatment plant located in upper Silesia. Water, 100, 12-23.

Łój-Pilch M, Zakrzewska A \& Zielewicz E (2018). Risk identification on the example of municipal sewage treatment plant. E3S Web of Conferences.

Malakahmad A, Downe A. G. Downe \& Fadzil S D M (2012). Application of occupational health and safety management system at sewage treatment plants,IEEE Business, Engineering \& Industrial Applications Colloquium (BEIAC), 2012, 347-350.

Mete T, Ozkan G \& Ozkan G (2012). Control of dissolved oxygen concentration using neural network in a batch bioreactor. Computer Applications in Engineering Education, 20(4), 619-628.

Mirghafouri S H \& Kousha A (2015). Risk Assessment of Water Transmission Pipelines with Fuzzy FMEA-AHP Approach (Case study: Yazd Water Transmission Pipeline). Journal of Applied Environmental and Biological Sciences, 5 (2015) 134-141.
Nicoleta U, Valentin V \& Gheorghe V (2020). Water scarcity and wastewater reuse in crop irrigation. Sustainability, 12, 1-18.

Özkan G, Akin B A \& Özkan G (2013). The prediction of chemical oxygen demand (COD) or suspended solid (SS) removal using statistical methods and the artifical neural network in the sugar industrial wastewaters. ARPN Journal of Engineering and Applied Sciences, 8(12), 978-983.

Özkan G, Uçan L \& Özkan G (2010). The Prediction of SO2 Removal Using Statistical Methods and Artificial Neural Network. Neural Computing and Applications, 1-9.

Radionovs A \& Rebrov O (2014). Application of fuzzy logic for risk assessment. Inf. Technol. Manage. Sci., 17(1):50-54.

Shang K \& Zakir H (2013). Applying Fuzzy Logic to Risk Assessment and Decision-Making Sponsored by CAS/CIA/SOA Joint Risk Management Section.

Shinta F R, Karnaningroem N \& Mardyanto A (2019). Risk Management of Wastewater Treatment in the Wastewater Treatment Plant of PT. X. The 1st International Conference on Business and Management of Technology (IConBMT), Institut Teknologi Sepuluh Nopember, Surabaya, Indonesia.

Stamatis D H (1995). Failure Mode and Effect Analysis: FMEA From Theory to Execution. ASQ, (Quality Press, Milwaukee), 1.

Subriadi A P \& Najwa N F (2020). The consistency analysis of failure mode and effect analysis (FMEA) in information technology risk assessment. Heliyon 6.

Suryoputro M R, Khairizzahra L, Amarria D S \& Nawang Wahyu W W (2019). Failure Mode and Effect Analysis (Fuzzy FMEA) Implementation for Forklift Risk Management in Manufacturing Company PT.XYZ IOP Conference Series: Materials Science and Engineering $528(1)$.

Yel E \& Yalpir S (2011). Prediction of primary treatment effluent parameters by Fuzzy Inference System (FIS) approach. Procedia Computer Science, 3, 659-665.

Yılmaz A (2015). Küresel ısınmanın dünya su rezervleri üzerindeki etkileri. Urban Academy Rewieved Journal of Urban Culture and Management, 8, 63-72. 